\title{
A case of male breast carcinoma
}

\section{Selma El Kadiri, Hanane Baybay, Rhizlane Chaoui, Zakia Douhi, Sara Elloudi, Fatima zahra Mernissi}

Department of Dermatology, Hassan II Hospital University, Fez, Morocco

Corresponding author: Dr. Selma El Kadiri, E-mail: elkadiri-s@hotmail.com

Sir

Male breast cancer is an uncommon disease of uncertain etiology representing $0.2-1.5 \%$ of all malignancies in men and $1 \%$ of all breast cancers. The diagnosis is most often delayed making the prognosis worse. We describe a 60-year-old man who presented with an ulcerated tumor in the left breast.

A 60 -year-old men presented with 2-year history of a painless, erythematous and bleeding lesion of the left nipple that was gradually increasing in size.

The patient was in otherwise good health without any significant past medical history.

Physical exam revealed an ulcerated plaque of the left nipple, measuring 3 centimeters, bleeding on contact, fixed to the underlying structures, with irregular contours (Fig. 1).

Axillary examination showed multiple lenticular bilateral axillary lymph nodes.However the abdomen was soft and no hepatosplenomegaly was noted.

Mammography showed an ulceration of the left mammary gland next to the nipple without visible opacity (Fig. 2).

A skin biopsy was performed and the histologic diagnosis was a non specific mammary carcinoma, grade II of Ellis and Elston, ulcerating the skin with positive hormone receptors.

Complete staging was performed. Lymph node ultrasound revealed a malignant lymphadenopathy at the left axillary measuring $1 \mathrm{~cm}$. Computed

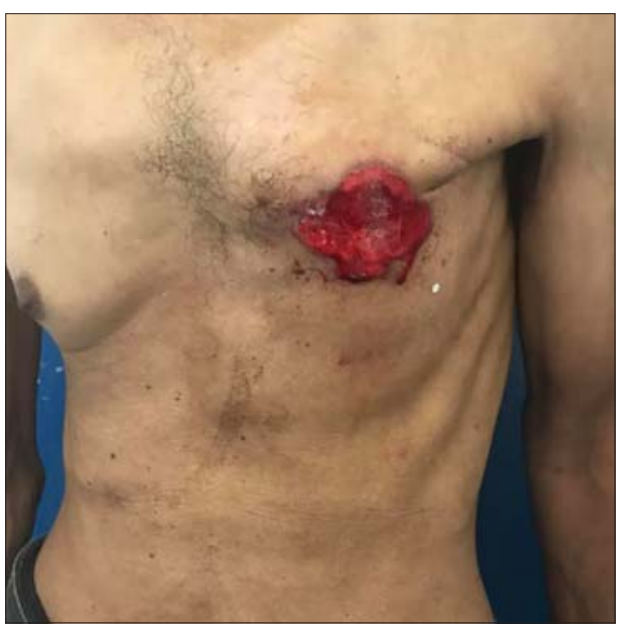

Figure 1: Ulcerated plaque of the left nipple, measuring 3 centimeters, bleeding on contact with irregular contours.

tomography scan of the neck,chest, abdomen, and pelvis demonstrated bone and pulmonary metastasis.

After a multi-disciplinary consultation meeting, the patient underwent a surgery, chemotherapy and adjuvant radiotherapy with good improvement (Fig. 3).

Breast carcinoma in men is rare which most often occurs at or after the age of 60 years. The cause of MBC (male breast carcinoma) remains unclear, however several risk factors were identified such as age of patient, genetic predisposition, anatomic factors and hormone metabolism abnormalities related to elevated estrogen or prolactin levels [1].

Clinically, different aspects of breast cancer has been reported such as a painless palpable mass under areolar, changes in the nipple (retraction, ulceration) and involvement of the areolar and periareolar skin [2].

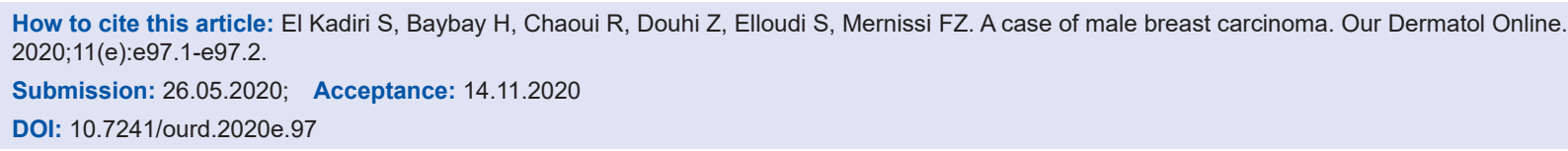




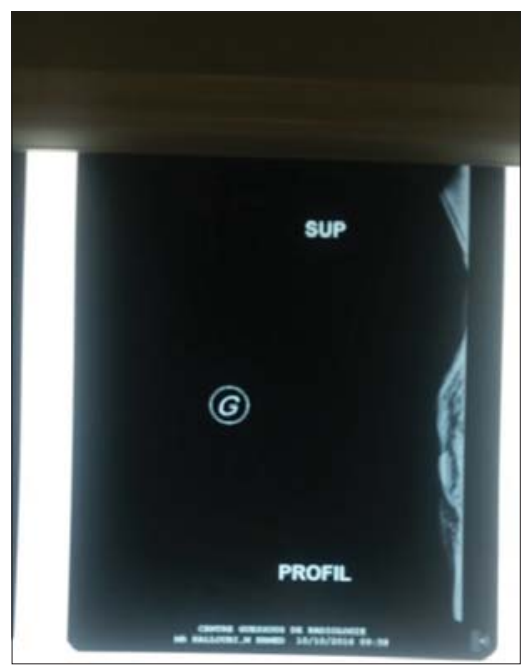

Figure 2: Mammography showed an ulceration of the left mammary gland next to the nipple without visible opacity.

Diagnosis is based on clinical examination, ultrasonography, and mammography [3].

Skin tumor invasion is more frequent and earlier in men than in women because of the small volume of the mammary gland.

All of the histologic types of carcinoma identified in the female breast have been encountered in men, with invasive ductal carcinoma being the most common [4].

Male breast cancer is rare, the prognosis in men remains uncertain because of the frequently late diagnosis, unpredictable course, and high potential for metastasis.

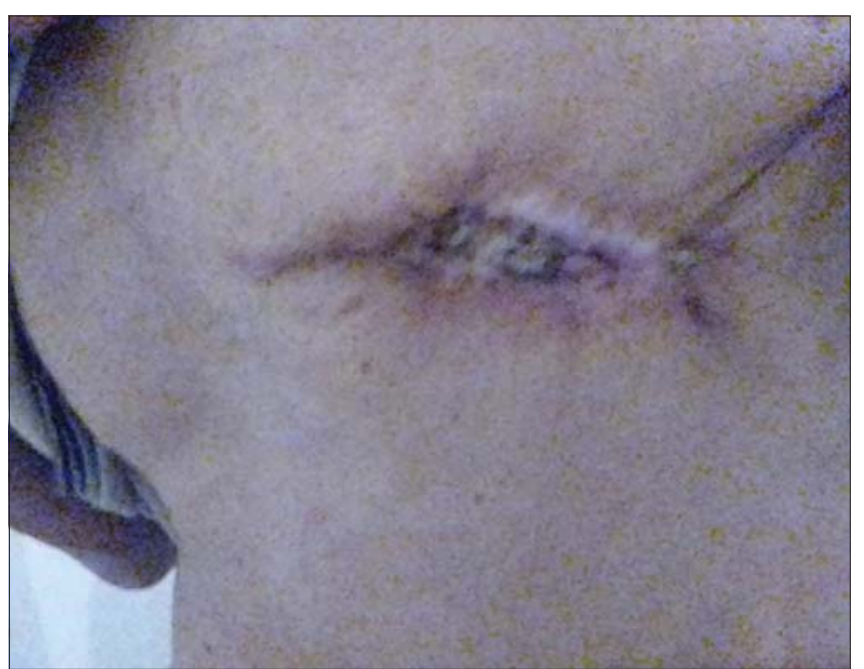

Figure 3: Complete healing of the lesion of the left breast.

\section{REFERENCES}

1. Jamy O, Rafiq A, Laghari A, Chawla T. Male breast cancer: a 24 year experience of a Tertiary Care Hospital in Pakistan. Asian Pac J Cancer Prev. 2015;16:1559-63.

2. Oger AS, Boukerrou M, Cutuli B, Campion L, Rousseau E, Bussières E, et al. Male breast cancer: prognostic factors, diagnosis and treatment: a multi-institutional survey of 95 cases. Gynecol Obstet Fertil. 2015;43:290-6.

3. Gucalp A, Traina TA, Eisner JR, Parker JS, Selitsky SR, Park BH, et al. Male breast cancer: a disease distinct from female breast cancer. Breast Cancer Research and Treatment. Breast Cancer Res Treat. 2019;173:37-48.

4. Saleh FM, Ansari NP. Invasive ductal carcinoma in a young male breast. Mymensingh Med J. 2012;21:162-4.

Copyright by Selma El Kadiri, et al. This is an open-access article distributed under the terms of the Creative Commons Attribution License, which permits unrestricted use, distribution, and reproduction in any medium, provided the original author and source are credited.

Source of Support: Nil, Conflict of Interest: None declared. 